\title{
PERANCANGAN AUGMENTED REALITY SEBAGAI MEDIA PROMOSI PADA MUSEUM NEGERI SUMATERA UTARA
}

\author{
Ayu Soraya \\ Mahasiswa Program Studi Pascasarjana Institut Seni Indonesia Padang Panjang \\ rayaupu07@gmail.com
}

\begin{abstract}
ABSTRAK
Museum Negeri Provinsi Sumatera Utara diresmikan tanggal 19 April 1982 oleh Daoed Yoesoef selaku Menteri Pendidikan dan Kebudayaan namun belum banyak yang mengetahui keberadaan Museum Negeri Sumatera Utara. Kurangnya media promosi menyebabkan jumlah pengunjung terus menurun setiap tahun. Perancangan media promosi yang komunikatif sesuai dengan target audience diharapkan mampu meningkatkan minat berkunjung ke Museum Negeri Sumatera Utara. Konsep perancangan dibuat menggunakan pendekatan media pembelajaran sehingga target audience akan lebih memahami museum dengan tampilan yang dikemas dalam bentuk 3Ddan menggunakan teknik Augmented Reality dan menggunakan marker sebagai pendukungnya. Marker yang digunakan dalam rancangan ini merupakan marker buatan bukan marker alami. Augmented reality adalah gabungan antara objek virtual dengan objek real. perancangan diwujudkan dalam sebuah aplikasi Augmented Reality yaitu "AR Sinolgi MuNeg SUMUT". Metode penciptaan yang digunakan dengan melakukan eksplorasi, menentukan perancangan dan mengimplementasikan rancangan yang telah di tetapkan. Penelitian ini menghasilkan aplikasi augmented reality sebagai media utama dan beberapa media pendukung lainnya seperti baju, mug, sepanduk, stiker, dan gantungan kunci
\end{abstract}

Kata Kunci: Museum, Sumatera Utara ,Perancangan, Augmented Relality “AR Sinolgi MuNeg SUMUT"

\section{ABSTRACT}

North Sumatra Province State Museum was inaugurated on April 19, 1982 by Daoed Yoesoef as Minister of Education and Culture, not many people understand about the North Sumatra State Museum. Lack of promotional media causes the number of visitors continues to decline every year. The design of communicative promotional media in accordance with the target audience is expected to increase interest in visiting the North Sumatra State Museum. The design concept is made using instructional media so that the target audience will consider the museum more with a display that is packaged in $3 D$ and uses Augmented Reality techniques and uses markers as a support. Markers used in this design are artificial markers not natural markers. Augmented reality is a combination of virtual objects with real objects. the design is realized in an Augmented Reality application that is "AR Sinolgi MuNeg SUMUT". The method used to explore, determine the design and implement the design that has been set. This research produces augmented reality application as the main media and several other supporting media such as clothes, mugs, banners, stickers, and key chains. 


\section{PENDAHULUAN}

Pada tanggal 19 April 1982 Museum Negeri Provinsi Sumatera Utara diresmikan oleh Daoed Yoesoef selaku Menteri Pendidikan dan Kebudayaan. Peletakan koleksi pertama tahun 1954 berupa makara dilakukan oleh Soekarno Presiden Republik Indonesia pertama. Museum Negeri Sumatera Utara dikenal dengan nama Gedung Arca karena koleksi pertama dalam museum ini berbentuk makara. Museum Negeri Provinsi Sumatera Utara berada di Jalan H. M. Joni No. 15 Medan. (http://www. Museumindonesia.com, diakses 30 Januari 2018)

Museum Negeri Provinsi Sumatera Utara merupakan museum bersejarah di Kota Medan, namun pengunjung belum menetapkan museum sebagai daftar urutan pertama sebagai tempat yang harus dikunjungi. Selain sebagai tempat wisata, museum juga dapat dijadikan sebagai tempat belajar anak-anak untuk mengetahui peninggalan sejarah di Sumatera Utara, tokoh-tokoh bersejarah di Kota Medan, mengenal etnis-etnis yang ada di Sumatera Utara.

Berdasarkan data dari Museum Negeri Sumatera Utara jumlah tamu yang berkunjung ke Museum Negeri Sumatera Utara setiap tahunnya terus menurun terlihat dari data grafik jumlah pengunjung. Tahun 2015 jumlah pengunjung 88.117 ribu orang, tahun 2016 sejumlah 82.549 ribu orang dan tahun 2017 sejumlah 50.048 ribu orang (Sumber: Kasi Koleksi dan Edukasi Museum Negeri Sumatera Utara tahun 2018). Meskipun diresmikan sudah cukup lama namun warga Medan Sumatera Utara masih banyak yang belum mengetahui keberadaan Museum Negeri Sumatera Utara. Hal ini dikarenakan kurangnya promosi dan sosialisasi kepada seluruh masyarakat.

Promosi yang telah dilakukan oleh Museum Negeri Sumatera Utara yaitu berupa brosur, buku panduan, banner, pameran nasional, pameran regional, sosialisasi, museum masuk sekolah, kerjasama dengan beberapa travel yang ada di Kota Medan dan melakukan event setiap tahunnya. Promosi yang dilakukan hanya dalam bentuk sosialisasi tidak disertai simulasi. Upaya promosi tersebut belum mampu meningkatkan jumlah peminat pengunjung di Museum Negeri Sumatera Utara.

Berdasarkan data yang diperoleh maka perlu ada inovasi perancangan media promosi dengan konsep yang berbeda dan sesuai dengan perkembangan zaman saat ini. Perancangan menurut Jogiyanto dalam bukunya Analisis dan Desain menjelaskan bahwa:

Perancangan merupakan sistem yang dapat menggambarkan, merencanakan dan membuat sketsa ataupunaturan dari beberapa bagian terpisah menjadi kesatuan utuh dan berfungsi yang dilakukan setelah tahap pengembangan siklus. (Jogiyanto, 2005:196)

Konsep perancangan dibuat menggunakan pendekatan media pembelajaran sehingga target audience akan lebih memahami museum dengan tampilan yang dikemas dalam bentuk 3D dan menggunakan teknik augmented reality. Menurut Ronald Azuma

Augmented realitymerupakangabungan objek virtual dan objek nyata bersifat interaktif secara real time dan berbentuk animasi 3D. Augmented reality lebih dikenal dengan istilah virtual realitymerupakan variasi dari virtual environment. (Azuma, 1997:2).

Augmented Reality dalam pengaplikasiannya memiliki tiga perangkat yaitu: see-through head-mounted display, virtual retinal display dan tampilan berbasis layar. 
Pada aplikasi yang pengkarya ciptakan memilih perangkat Tampilan Berbasis Layar karena disesuaikan dengan target audience.

Pemilihan media augmented reality dianggap lebih efektif, menarik dan komunikatif dalam penyampaiannya sehingga lebih mudah dipahami oleh masyarakat. Pemanfaatan teknologi augmented reality koleksi museum disajikan secara virtual dengan objek 3D tidak hanya dalam bentuk teks dan gambar, akan tetapi menampilkan bagian-bagian dari koleksi museum beserta keterangannya. Koleksi museum tersebut didesain sesuai dengan bentuk aslinya sehingga masyarakat dapat mengetahui bentuk asli koleksi tersebut, kemudian setiap satu koleksi dilengkapi dengan satu marker.

Media utama yang pengkarya rancang adalah Augmented Reality., Selain media utama pengkarya juga merancang media pendukung seperti $T$-Shirt, gantungan kunci, tiket masuk museum, mug, stiker, notebook, x-banner, poster, brosur dan website. Tujuan dirancangnya media pendukung adalah sebagai pendukung media utama perancangan. Penentuan media pendukung disesuaikan dengan kebutuhan dari Museum Negeri Sumatera Utara.

\section{STUDI LITERATUR}

Metode penciptaan yang digunakan pada penelitian ini meliputi proses eksplorasi, perancangan, dan implementasi. Tinjauan Karya penciptaan dilakukan untuk menghindari duplikasi, dan mengetahui karya seni diciptakan sudah pernah ada sebelumnya, agar orisinalitas karya seni terbukti. Karya pertama yang menjadi rujukan berjudul Animating 100 year old dioramas at the American Museum of Natural History. Developed by Ori Inbar and Snowball VFX, 22 November 2013.

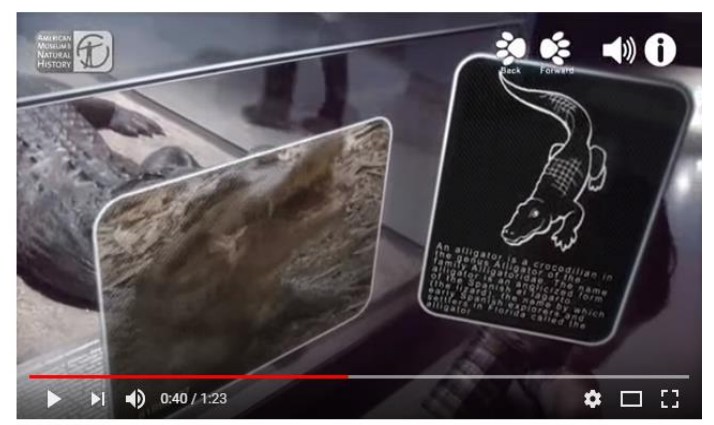

Gambar 1 : Augmented Reality Demo for American Museum of Natural History

(Sumber : Screenshot dari Youtube, diakses 31 Januari 2018)

Dalam perancangan pembuatan karya Augmented Reality ini pengkarya juga melihat karya Augmented Reality yang pernah dipublikasikan oleh Ori Inbar pada 22 November 2013 dengan tema yang sama. Karya yang dipublikasikan oleh Ori Inbar ini menampilkan dua objek berupa video asli dan gambar vektor yang disertai keterangan. Karya ini menampilkan dua tampilan yang memiliki tujuan sama. Persamaan dengan aplikasi yang pengkarya rancang adalah menggunakan teknik yang sama yaitu augmented reality untuk semua kalangan bertujuan sebagai fasilitas yang diberikan pengelola kepada pengunjung dan diaplikasikan di tempat yang sama yaitu Museum. Perbedaan dengan yang pengkarya rancang adalah aplikasi yang pengkarya rancang ditujukan untuk anak-anak dan pelajar dan sebagai media promosi Museum Negeri Sumatera Utara agar lebih mencintai sejarah dan mengenang perjuangan masa lalu.

Selanjutnya yaitu aplikasi berjudul Beacon technology applied to modern art museum in Krakow yang dipublikasikan oleh Muzeum Sztuki Współczesnej w Krakowie MOCAK, 04 Februari 2015. 


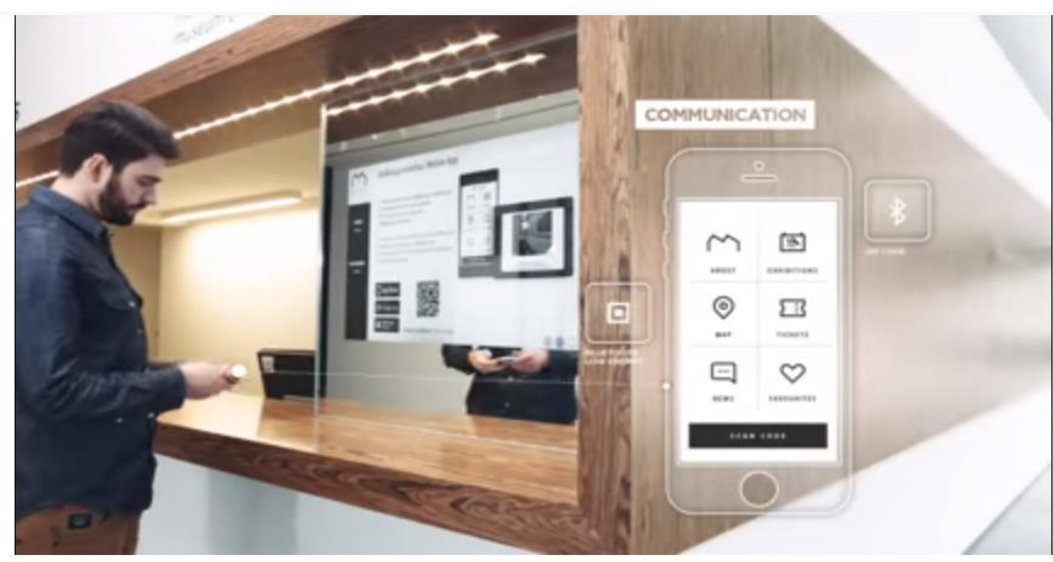

Gambar 2 : Beacon technology applied to modern art museum in Krakow (Sumber : Screenshoot Youtube Canel, diakses 31 Januri 2018)

Aplikasi Museum Beacon technology applied to modern art museum in Krakow merupakan aplikasi mobile yang dirancang untuk membantu pengunjung menentukan arah kunjungan di museum dan menjadi pemandu arah letak koleksi yang ada di museum. Navigasi dirancang menggunakan kode QR dan perangkat $H G$ Beacon yang inovatif, sehingga memudahkan penggunanya. Fungsi dari aplikasi ini hampir sama yaitu sebagai salah satu media yang digunakan untuk menarik pengunjung dengan adanya aplikasi modern yang dapat menunjukkan arah letak lokasi koleksi museum sehingga memudahkan pengunjung. Hal yang membedakan adalah karya yang pengkarya rancang berupa aplikasi augmented reality sebagai media promosi menampilakn objek koleksi dalam bentuk 3D dengan tampilan yang lebih nyata sehingga lebih mudah dipahami oleh target audience.

Tinjauan karya penciptaan juga merujuk pada tesis yang berjudul Perancangan Augmented Reality sebagai Media Promosi Pada Museum Negeri Sumatera Utara tahun 2018. Tesis yang di rujuk menjelaskan proses perancangan augmented reality museum dan fitur-fitur yang terdapat pada aplikasi augmented reality. Pada tesis yang dirujuk menjelaskan augmented reality sebagai media utama dan beberapa media sebagai media pendukung.

\section{PEMBAHASAN}

\section{Segmentasi Target Audience}

Untuk mengetahui kebutuhan, karakteristik atau tingkah laku dari target audience pada perancangan media promosi, diperlukan segmentasi target audience yaitu:

a. Demografi

Usia : Semua Umur (umum), 17-18 tahun (khusus)

Pendidikan : Semua Kalangan (umum), SMA (khusus)

Jenis Kelami : Laki-laki dan Perempuan

b. Geografis

Secara geografis target audience perancangan augmented reality Museum Negeri Sumatera utara adalah pelajar di Kota Medan dan masyarakat umum.

c. Psikografis

Secara Psikografis target audience yang ingin dicapai adalah pelajar SMA dan Masyarakat Umum yang memiliki rasa keingintauan tinggi mengenai peninggalan sejarah Sumatera Utara sehingga mampu menambah wawasan bagi Pelajar SMA. 


\section{d. Behavioral}

Augmented Reality dirancang untuk pelajar SMA yang tertarik pada sejarah kebudayaan Sumatera Utara dan suka mengunjungi tempat-tempat bersejarah di Sumatera Utara.

\section{Creative Brief}

Konsep penggarapan karya untuk pemecahan masalah berdasarkan ilmu desain komunikasi visual di perlukan creative Brief . Dalam rancangan ini creative Brief yang dirancang yaitu:

1. Mengapa harus merancang augmented reality pada Museum Negeri Sumatera Utara ?

Warga Medan Sumatera Utara masih banyak yang belum mengetahui keberadaan Museum Negeri Sumatera Utara meskipun berdiri sudah cukup lama, kurangnya minat pelajar tentang kebudayaan, anggapan bahwa museum adalah tempat yang kuno dan tempat barang rongsokan. Setiap tahun jumlah pengunjung di Museum Negeri Sumatera Utara terus menurun. Media promosi yang digunakan masih dalam sosialisasi tidak disertai simulasi. Konsep perancangan dengan menggunakan pendekatan media pembelajaran dengan tampilan yang dikemas dalam bentuk 3Ddengan menggunakan teknik augmented reality diharapkan mampu meningkatkan minat target audience.

2. Siapa Target audience?

Target audience dalam rancangan ini adalah pelajar SMA pada khususnya dan masyarakat pada umumnya untuk membangkitkan kembali kenangan masa lalu tentang sejarah perjuangan.

3. Apa yang ingin mereka fikirkan dan lakukan?

Ternyata museum tidak kuno seperti apa yang kita fikirkan, seiring perkembangan teknologi museum juga mampu menghadirkan media promosi yang berbasis teknologi.

4. Apa yang harus dikatakan?

Nostalgia Sejarah Sumut"Kepoin Yuk.."

5. Mengapa harus percaya?

Penggunaan konsep augmented reality pada promosi Museum Negeri Sumatera Utara menjadikan museum tempat yang menarik untuk dikunjungi selain untuk berwisata juga sebagai tempat untuk belajar karena Museum Negeri Sumatera Utara menyimpan kenangan masa lalu sejarah perjuangan di daerah Suamtera Utara.

6. Hal yang perlu dipertimbangkan?

Pemilihan warna pada pengaplikasian karya disesuaikan dengan psikologi warna dari target audience yaitu anak SMA dan penggunaan media pendukung disesuaikan dengan kebutuhan museum

Aplikasi augmented reality dirancang menggunakan visualisasi 3 dimensi untuk dapat menampilkan objek secara nyata. Perancangan karya ini mengambil 10 (sepuluh) sample dari perwakilan masing-masing kelompok koleksi yaitu: Rumah adat Sumatera Utara, alat musik Sumatera Utara, baju adat Sumatera Utara, ragam hias Sumatera Utara, peti mati Sumatera Utara, permainan zaman dulu, harimau Sumatera, manusia Purba, transportasi zaman dulu dan motif tenun. Pengambilan 10 (sepuluh) sample berdasarkan teknik promosi yang diambil, yaitu teknik persuasif yang hanya menampilkan beberapa objek guna menarik perhatian target audience.

\section{Augmented Reality}

Perangkat - perangkat yang digunakan dalam Augmented realityyaitu: 


\section{See-Through Head-Mounted Display}

See-through HMDpenyerapan cahaya dari lingkungan luar, yang memungkinkan pengguna dapat secara langsung melihat dunia nyata dengan mata.

\section{Virtual Retinal Display}

Virtual retinal displays (VRD) disebut juga retinal scanning display (RSD), proyeksi cahaya terhadap retina mata user secara langsung.

3. Tampilan Berbasis Layar

Sistem berbasis layar dapat memproyeksikan gambar kepada pengguna menggunakan layar proyeksi. Perangkat genggam yang memiliki terdapat tampilan layar LCD dan kamera merupakan media pengaplikasian utama pada tampilan berbasis layar. Perangkat genggam berfungsi seperti kaca pembesar atau jendela,mampu menambah bendavirtualtampilan dunia nyata yang mampu ditangkap kamera.(https://id.wikipedia.org/wiki/Realitas_tertambah, diakses pada 20 Februari 2018)

Perancangan Augmented Reality sebagai Media Promosi pada Museum Negeri Sumatera Utara dirancang menggunakan perangkat tampilan berbasis layar. Perangkat tampilan berbasis layar dipilih karena dibandingkan semua perangkat, perangkat ini merupakan yang paling sederhana dan sesuai dengan target audience rancangan pengkarya. Penggunaan perangkat See-Through Head-Mounted Display dan Virtual retinal displays membutuhkan perangkat yang lebih canggih dan proses yang panjang dalam pengerjaannya, selain itu membutuhkan alat yang lebih canggih untuk mengakses aplikasi yang diciptakan.

\section{PROSES PENCIPTAAN}

\section{a. Eksplorasi}

Eksplorasi merupakan tahap awal dalam perancangan aplikasi ini. Kota Medan merupakan kota ketiga terbesar setelah Jakarta dan Surabaya. Status sebagai kota terbesar ketiga tentunya membuat kota Medan mengalami perkembangan teknologi yang sangat pesat. Hal ini sangat berpengaruh terhadap perilaku masyarakat di kota Medan terutama anak-anak ramaja. Terlihat dari kebiasaan anak remaja sekarang yang lebih tertarik dengan hal modern dibandingkan dengan mengetahui kebudayaan serta peninggalan sejarah Sumatera Utara yang salah satunya tersimpan di Museum Negeri Sumatera Utara.

\section{b. Perancangan}

Perancangan adalah proses pembuatan konsep desain. Konsep disusun mulai dari menetapkan solusi desain, pemilihan media, pembuatan rancangan aplikasi, pemilihan warna, serta study layout. Solusi media yang dipilih yaitu media augmented reality karena karena dapat menampilkan objek museum dalam bentuk 3D secara nyata dan real time dengan bantuan marker.

\section{Perancangan Objek 3D}

Perancangan aplikasi dimulai dari pengambilan 10 (sepuluh) objek foto yang akan divisualisasikan dalam bentuk 3D menggunakan aplikasi 3Dmax, setelah proses pembentukan objek 3D maka kemudian dirancang marker sebagai penanda masingmasing objek 3D. 


\section{Perancangan Marker}

Perancangan marker dimulai dari pembuatan pola marker menggunakan photoshop CS6 dan kemudian setelah marker selesai dirancang maka disimpan ke dalam sebuah database serta diberi nama sesuai objek 3D yang telah dirancang menggunakan aplikasi Unity. Pada Aplikasi Unity terjadi proses penggabungan objek 3D dan Marker yang telah disimpan di dalam database sehingga terbentuklah aplikasi Augmented Reality.

Perancangan Augmented reality juga dilengkapi beberapa keterangan dan tidak terlalu detail bertujuan untuk menarik pengunjung untuk berkunjung ke museum. Teknik promosi yang dilakukan menggunakan teknik persuasif hanya menampilkan beberapa jenis koleksi museum dengan keterangan sejarah agar mampu menarik perhatian target audience berkunjung ke museum untuk melihat koleksi yang lebih lengkap. Software yang digunakan adalah 3Dmax dan Unity.

\section{c. Implementasi}

Dalam proses implementasi pertama yaitu pengimplementasikan modeling 3D menggunakan software 3Dmax yang berasal dari foto objek yang telah diperoleh melalui riset yang telah dilakukan. Kedua yaitu pengimplementasian marker, yaitu dengan membuat desain gambar untuk tracking objek aplikasi, marker yang telah dibuat disimpan dalam library dan dibedakan untuk masing-masing objek. Komponen utama yaitu objek dan marker yang telah diciptakan akan dibangkitkan melalui proses builder menggunakan aplikasi Vuforia SDK. Perancangan marker menggunakan aplikasi pengolahan grafis, yaitu menggunakan Adobe Photoshop CS6.

Perangkat lunak yang digunakan untuk mengembangkan aplikasi Augmented Reality menggunakan softwareUnity. Media yang dapat memproyeksikansuatu objek maya terhadap objek realpada aplikasi Augmented Realitymemerlukan metode pelacakan berupa Marker. Marker inilah yang nantinya yang akan di deteksi oleh kamera untuk menampilkan objek yang telah dirancang.

\section{Visualisasi Objek 3D}

Pengkarya menggunakan software 3DMax untuk membuat objek 3D visualisasi objek Museum. Gambar 3D yang dibuat untuk visualisasi objek Museum berjumlah 10. Gambar 3D Objek Museum dapat dilihat pada tabel di bawah ini:

Tabel 1. Tampilan Desain 3D

\begin{tabular}{|c|c|c|}
\hline No & $\begin{array}{c}\text { Tampilan Desain 3D 10 } \\
\text { Sempel Koleksi Museum }\end{array}$ & Keterangan \\
\hline & & Miniatur Sapo Page (Karo) \\
\hline 1. & & \\
\hline
\end{tabular}




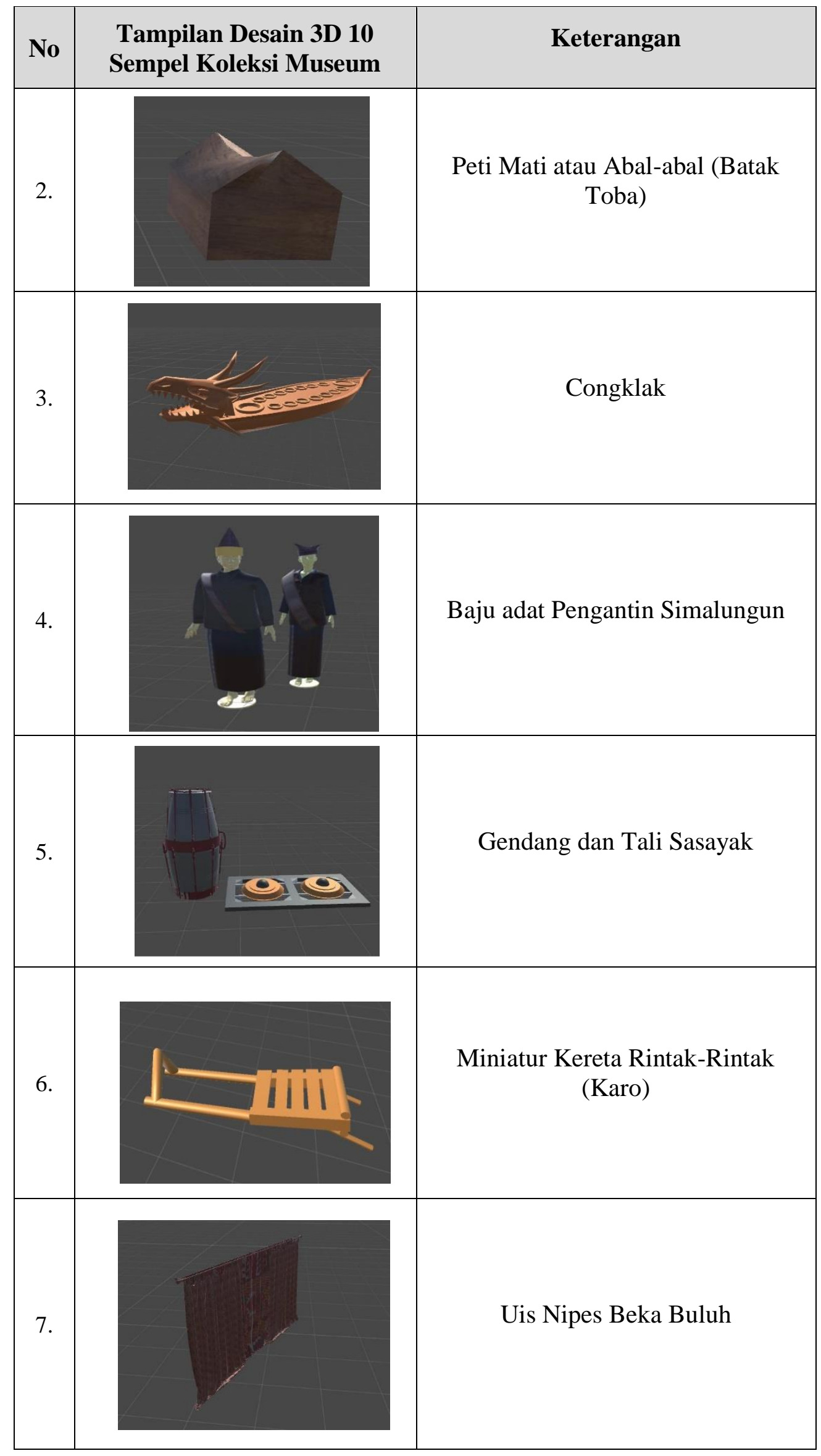




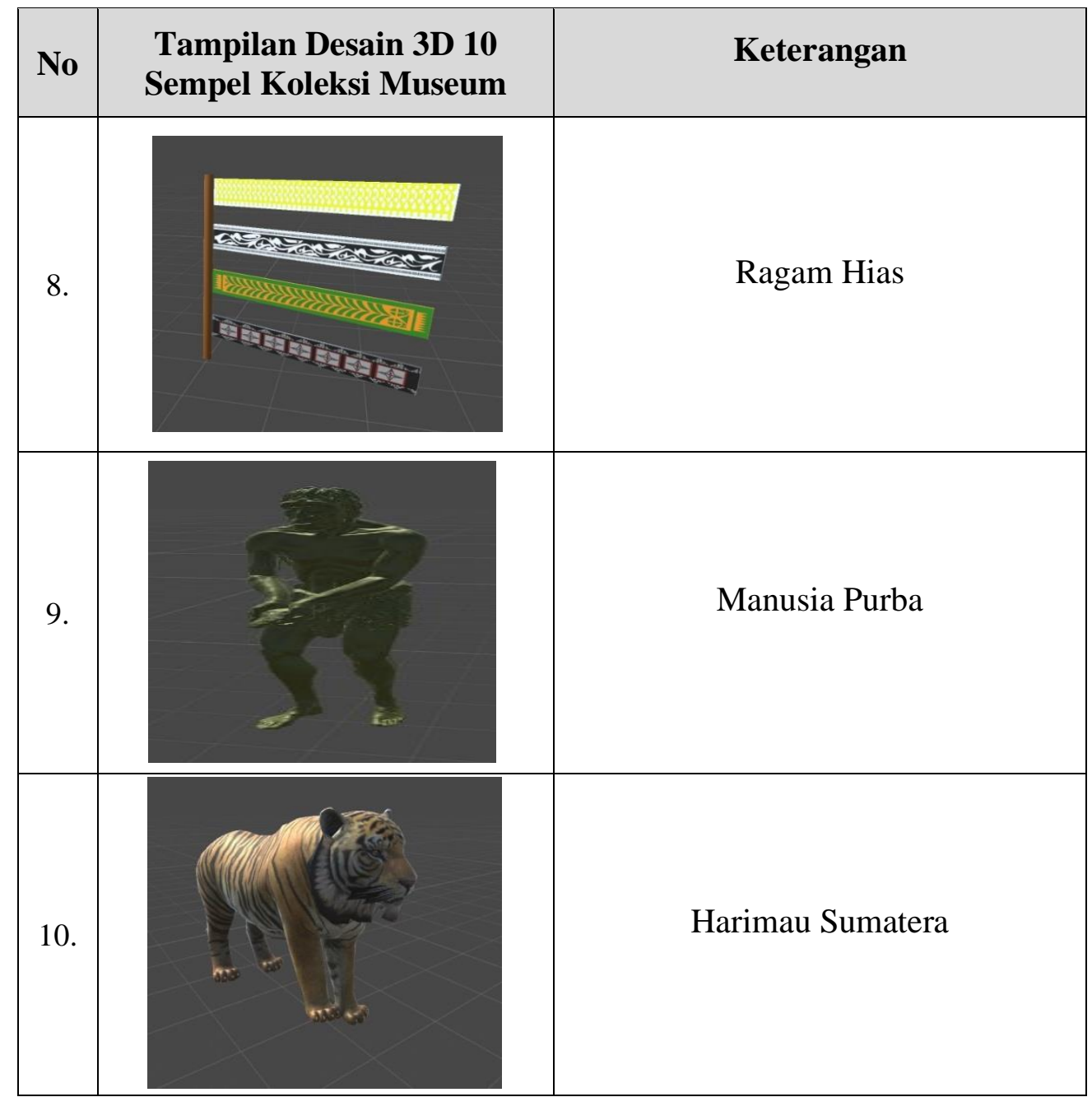

\section{Proses Kerja Unity}

Perangkat mobile yang dirancang dan di program dengan menggunakan aplikasi Unity. Proses kerja Unity terbagi menjadi lima yaitu: Langkah pertama arahkan kamera ke marker, kemudian marker yang dideteksi berubah menjadi binary dan dapatdikenali oleh kamera. Selanjutnya Kamera mendeteksi posisi marker 3Dimensi dan diperhitungkanmenggunakan kamera nyata. Kemudian Kamera mengidentifikasi marker, bagaimana pola markerdisesuaikan dengan templates memory kemudian kamera mentransformasikan posisi marker. Terakhir Objek 3D museum dirender diatas marker. Berikut merupakan gambar proses kerja Unitysecara detail.

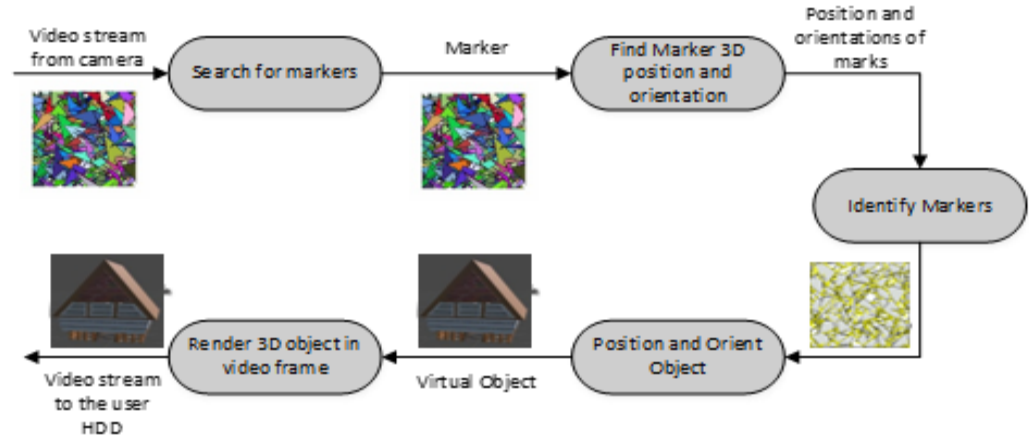

Gambar 3. Alur Kerja Unity 


\section{Marker}

Marker pada Augmented reality dapat dibedakan menjadi dua yaitu: marker dan markerlessyang dibedakan berdasarkan ada tidaknya penggunaan marker(Geroimenko, 2012). Foto objek dunia nyata ataupun suatu gambar buatan pola yang unik terdiri dari garis dapat dijadikan sebuah Marker. Metode markerlessmerupakan salah satu metode pelacakan augmented realityyang menjadikan dunia nyata sebagaimarkerbukanmarker buatan.

Software yang digunakan adalah Adobe Photoshop CS6 untuk membuat marker sebagai penanda dari masing-masing objek 3D museum. Jumlah marker sesuai dengan jumlah objek museum yang menjadi sampel yaitu 10. Marker diletakkan pada desain brosur museum dan media pendukung lainnya. Pada rancangan ini pengkarya menggunakan marker warna dikarenakan marker warna lebih mudah terdeteksi oleh aplikasi dan lebih menarik. Marker yang pengkarya rancang memiliki motif yang sama, hal ini dengan tujuan untuk lebih menambah tingkat ketertarikan dan rasa penasaran dari target audience. Di bawah ini merupakan gambar marker yang telah dirancang sebagai berikut:
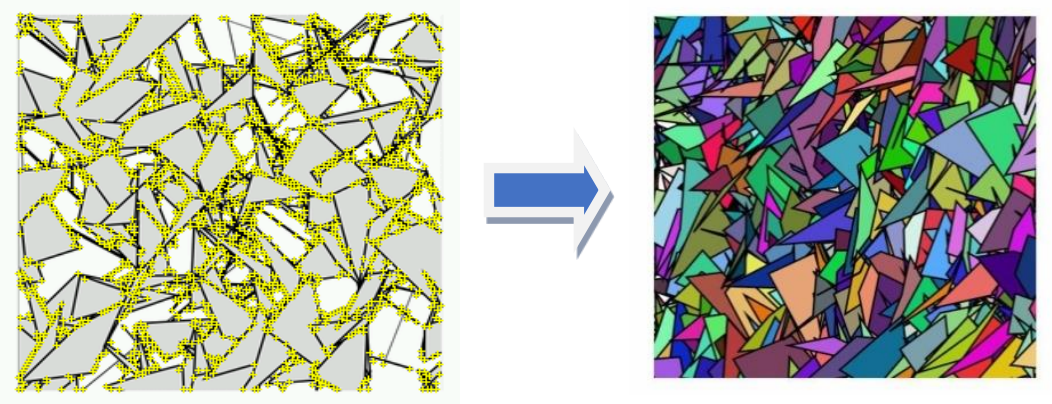

Gambar 4. Marker

(Sumber: Ayu Soraya, 2018)

\section{Studi Warna}

Pemilihan warna yang digunakan pada perancangan Augmented Reality sebagai Media Promosi pada Museum Negeri Sumatera Utara adalah warna cerah, hal ini disesuaikan dengan psikologi target audience yaitu remaja setingkat pelajar SMA dan unsur budaya batak.

Menurut Dameria (2007: 10), warna terbentuk melalui 3 unsur berupa cahaya, objek dan observer dimana caya tidak dapat terlihat apabila berada diruang yang gelap. Tanpa adanya cahaya maka warna tidak dapat dikenali dan dengan mata tertutupobjek tidak terlihat, objek yang tidak terlihat maka warna tidak dapat dikenali.

Pemilihan warna mampu mempengaruhi susasana psikologis seseorang, menurut Pujiriyanto (2005:43), warna erat hubungannya dengan lingkungan dalam kompisisinya. Warna memiliki kekuatan tersendirijika dikeluarkan dari lingkarannya. Keluasannyakualitas dan kuantitas menjadi faktor yang sangat mendukung.

Berdasarkan hal-hal tersebut, maka dalam rancangan ini pengkarya memilih warna-warna cerah seperti warna kuning, hijau, light pink, biru, putih, merah dan hitam. Warna-warna cerah dipilih karena disesuaikan dengan target audience dan menurut psikologi warna, warna cerah menumbuhkan keceriaan. Warna dominan yang digunakan adalah warna biru, putih, merah dan hitam yang di terapkan pada media pendukung. Warna biru bersifat dingin, damai dan melambangkan harapan, keakraban dan kebersamaan. Warna putih bersifat bersih, cemerlang dan melambangkan perdamaian, kepolosan dan kesopanan. Warna hitam bersifat gelap dan melambangkan 
ketegasan. Pada rancangan ini unsur kebudayaan ditonjolkan memalui warna merah dan hitam yaitu warna khas batak.

\section{Studi Tipografi}

Tipografi merupakan susunan huruf alfabet yang merupakan salah satu media penting dalam perancangan augmented reality. Menurut Pricilia Yunita Wijaya (1999: 5) Dalam sebuah karya desain, semua elemen yang ada saling berkaitan. Pemilihan tipografi memperhatikan prinsip-prinsip dalam tipografi. Empat prinsip tipografi yang mampuberpengaruh terhadap keberhasilandalam sebuah desain, prinsip tersebut meliputi legability, clarity, visibility, dan readibility.

Berdasarkan dari prinsip-prinsip tersebut. Berikut adalah alternatif font perancangan:

\section{Kepoin yuk Kepoîn guk Kepoin yuk Roboto Snap ITC Bouhaus 93}

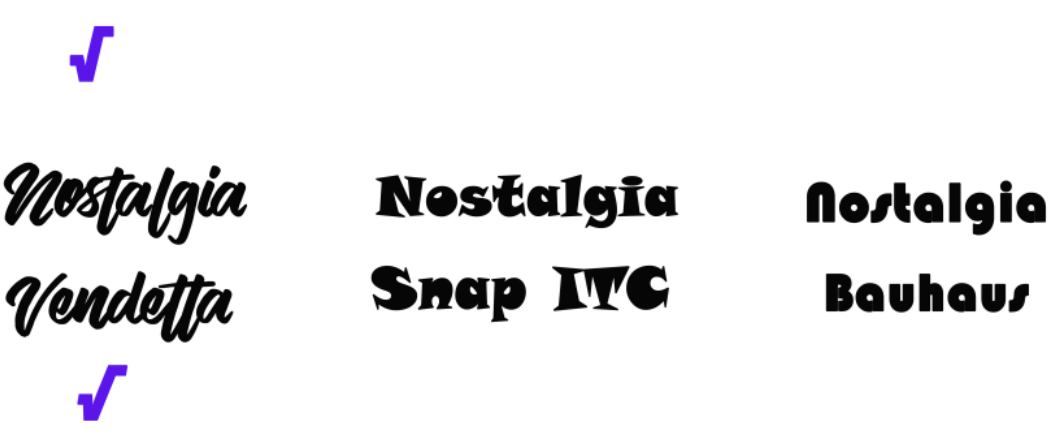

Gambar 5: Alternatif Font Perancangan

(Sumber: Ayu Soraya, 2018)

Berdasarkan analisis prinsip-prinsip typografi maka jenis typografi yang sesuai untuk digunakan pada karya ini adalah roboto dan vendetta. Roboto memiliki karakter yang tegas yang diaplikasikan pada tagline "Kepoin yuk..." yang menunjukkan ketegasan untuk berkunjung ke Museum. Vendetta yang diaplikasikan pada tagline "Nostalgia Sejarah Sumut" sesuai dengan taglinenya yaitu nostalgia, hal ini menunjukkan kisah masa lalu.

\section{d. Sosialisasi}

Tahap ini adalah tahap memperkenalkan karya yang telah dirancang kepada pihak Museum Negeri Sumatera Utara. Sosialisai yang dilakukan melalui presentasi dan simulasi aplikasi agar pihak museum memahami dan mengaplikasikan aplikasi rancangan pengkarya. Pengkarya memperkenalkan fitur-fitur yang terdapat dalam aplikasi dan memnunjukkan media pendukung aplikasi yang telah pengkarya rancang. 


\section{HASIL}

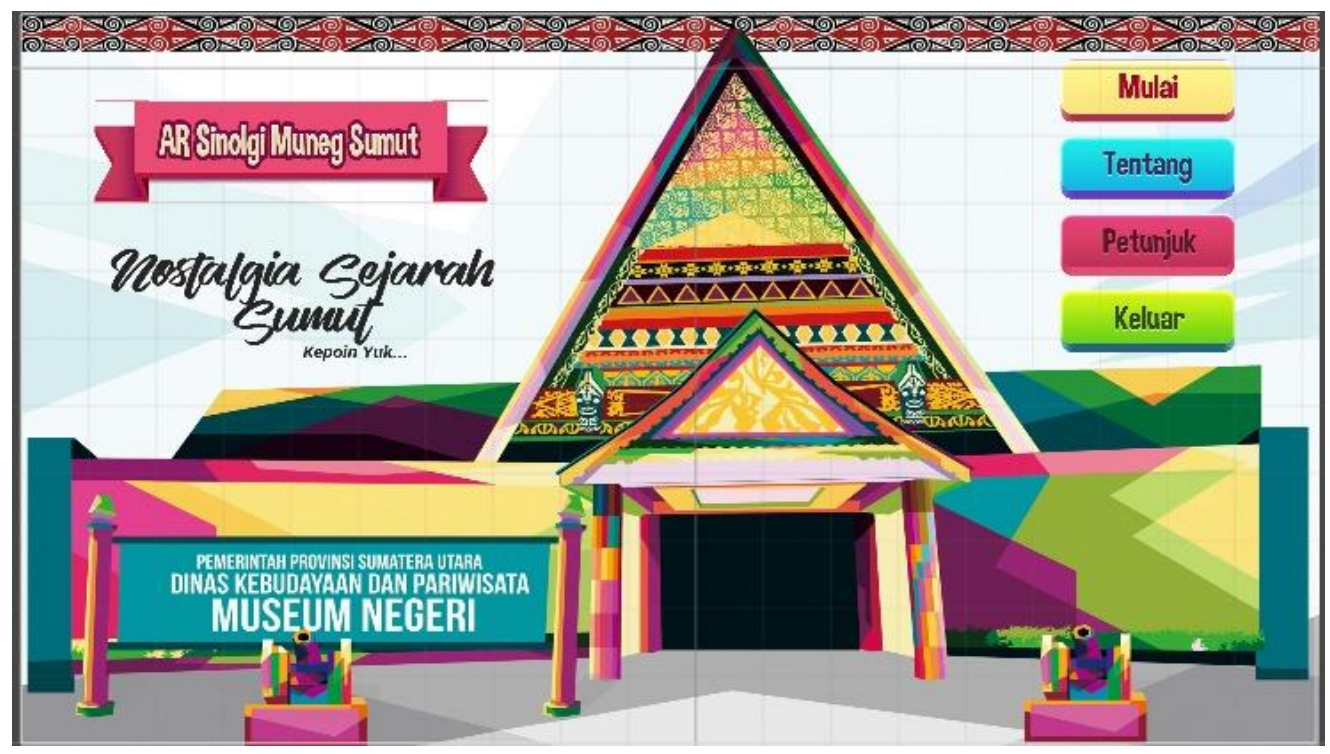

Gambar 6. Alternatif 3 Halaman Utama

(Sumber: Ayu Soraya, 2018)

\section{KESIMPULAN}

Augmented Reality merupakan suatu aplikasi gabungan antara objek virtual dengan objek nyatabersifat lebih interaktif dan ditampilkan dalam bentuk 3Dimensi sehingga lebih menarik, untuk menjalankan aplikasi di perlukan sebuah marker untuk mendeteksi sebuah objek yang akan ditampilkan.Rancangan Augmented Reality Sebagai Media Promosi pada Museum Negeri Sumatera Utara diwujudkan dalam sebuah aplikasi android sebagai media utama. Dalam rancangan ini selain media utama, dirancang juga media pendukung yang sebagian besar dalam bentuk merchandise sehingga dapat berfungsi untuk mendukung keberhasilan dari media utama seperti: T-Shirt, gantungan kunci, tiket masuk museum, mug, stiker, notebook, x-banner, poster, brosur dan website. Media pendukung nantinya akan dibagikan sebagai reward di event-event yang dilaksanakan oleh Museum Negeri Sumatera Utara dan dapat dibeli di toko souvenir Museum Negeri Sumatera Utara.

\section{DAFTAR PUSTAKA}

[1] Dameria, Anne. 2007. Color Basic. Jakarta : Penerbit Link \& Match Graphic.

[2] Geroimenko, V. 2012. "Augmented Reality Technology and Art: The Analysis and Visualization of Evolving Conceptual Models. Information Visualisation (IV)" dalam 2012 16th International Conference (pp. 445- 453). IEEE.

[3] Kusmiati R, Artini. dkk. 1999. Teori Dasar Desain Komunikasi Visual. Jakarta: Djambatan.

[4] Jefkins, Frank. 1997. Periklanan. Jakarta: Erlangga

[5] Jogiyanto. 2005. Analisis dan Desain Sistem Informasi. Yogyakarta: Penerbit Andi. 
[6] Priscilia, Tipografi Dalam Desain Komunikasi Visual. Jurnal NIRMANA. Universitas Kristen Petra

[7] Pujiriyanto. 2005. Desain Grafis Komputer. Yogyakarta: Andi.

[8] Suptandar, Pamudji. 1995. Manusia dan Ruang dalam Proyeksi Desain Interior. Jakarta: UPT Penerbitan Universitas Tarumanegara

[9] Winardi. 2000. Kepemimpinan dalam Manajemen. Jakarta: Rineka Cipta

[10] R. Azuma. 1997. "A survey of Augmented Reality," Presence Teleoperators Virtual Environ, vol. 6, no. 4, pp. 355-385. www.cs.unc.edu/ azuma/ARpresence.pdf, diakses tanggal 5 Februari 2018.

https://www.researchgate.net/publication/258514340, diakses 14 Februari 2018

https://museumku.wordpress.com/2010/04/15/museum-negeri-provinsi-sumatera-utara/, diakses 14 Februari 2018

http://www.museumindonesia.com/museum/33/1/museum_negeri_provinsi_sumatera_utar a_medan, diakses 14 Februari 2018

http://www.Youtube.com, diakses 31 Januari 2018

https://id.wikipedia.org/wiki/Realitas_tertambah, diakses pada 20 Februari 2018

https://support.apple.com/id-id/HT204657, diakses tanggal 04 Juni 2018

www. wikipedia.com 